\title{
ATIVIDADE DE CAMPO NO ENSINO SUPERIOR: UM ESTUDO DE CASO ETNOGRÁFICO
}

\author{
Emerson Ferreira da Silva ${ }^{1}$ \\ Julie Mathilda Semiguem Pavinato ${ }^{2}$ \\ Daniela Savi ${ }^{3}$ \\ Alvori Ahlert ${ }^{4}$
}

Resumo: A atividade de campo é uma ferramenta de ensino muito utilizada na educação básica. Este artigo, no entanto, tem como objetivo analisar a importância da atividade de campo para a Educação Ambiental no ensino superior. Para isso, foi realizado um estudo de caso etnográfico com uma turma de pós-graduação em Desenvolvimento Rural Sustentável, da Universidade Estadual do Oeste do Paraná. Além da observação participante, também foram realizadas entrevistas semiestruturadas com os participantes onde se pôde confirmar efeitos positivos proporcionados pela referida atividade. Verificou-se que a atividade relatada neste trabalho contribuiu para melhor assimilação dos conteúdos trabalhados em sala de aula, inclusive despertando para o desejo de alguns participantes em multiplicar ações semelhantes.

Palavras-chave: Educação Ambiental; Atividade de campo; Sensibilização.

${ }^{1}$ Professor da Educação básica, técnica e tecnológica do IFPR. Discente do Programa de Pós-Graduação em Desenvolvimento Rural Sustentável pela UNIOESTE - Universidade Estadual do Oeste do Paraná; Graduado em Ciências Sociais pela UEM- Universidade Estadual de Maringá. E-mail: emerson.ferreira@ifpr.edu.br.

2Professora do Curso de Administração da Faculdade Dom Bosco/ Ubiratã-PR. Discente do Programa de Pós-Graduação em Desenvolvimento Rural Sustentável - PPGDRS pela UNIOESTE - Universidade Estadual do Oeste do Paraná. E-mail: julie_pavinato@hotmail.com.

3 Graduada em Administração pela União dos Cursos Superiores SEB. Discente do Programa de PósGraduação em Desenvolvimento Rural Sustentável - PPGDRS pela UNIOESTE - Universidade Estadual do Oeste do Paraná. E-mail: savi.daniela@hotmail.com.

4 Professor Associado da Universidade Estadual do Oeste do Paraná - UNIOESTE, pesquisador e docente do Programa de Pós Graduação em Desenvolvimento Rural Sustentável - PPGDRS, UNIOESTE. Email:alvoriahlert@yahoo.com.br. 


\section{Introdução}

A questão ambiental é uma problemática assimilada por praticamente todas as pessoas, não importando a qual estrato social ou nível de escolarização pertençam. Mesmo que a ideia da necessidade de preocupação com o meio ambiente seja bastante difundida, ainda faltam muitas informações sobre esse cuidado na prática. A maioria das pessoas têm contato com este tema de maneira superficial, inclusive no meio acadêmico, onde a ampla grade de conteúdos existentes nos cursos superiores acaba contribuindo para que tal debate não assuma a importância necessária para despertar uma conscientização ambiental mais profunda. Bacci, Silva e Sorrentino (2015), em um estudo sobre a Educação Ambiental no ensino superior, argumentam que "não há dúvidas sobre a importância da uma formação ambiental na Educação Superior em todas as áreas do conhecimento, suportada pela legislação" (p.13). Todavia, a pesquisa realizada pelos autores constatou que "há um privilégio concedido aos aspectos técnicos e operacionais numa abordagem predominantemente químico-biológicotécnico nas disciplinas que abordam o meio ambiente" (BACCl et al, 2015, p.13).

Atualmente, a necessidade de preservação ambiental, embora seja uma ideia bastante consolidada, acaba esbarrando em um comportamento apresentado por diversos setores da sociedade como sendo o único possível, devendo ser seguido por todos. Esse estilo de vida, baseado no hábito da aquisição de um volume exacerbado de mercadorias, muitas delas desnecessárias, leva a maioria das pessoas a uma corrida para manter determinados padrões de consumo (MARCONDE FILHO, 1985). Essa prática, que vai ao encontro apenas dos interesses dos grandes grupos econômicos, que têm os valores do mercado acima de quaisquer outros, estimula as pessoas a terem um estilo de vida onde o foco no trabalho e no consumo deixa pouco espaço para a reflexão, sobretudo com relação às questões ambientais.

Para o modelo econômico predominante no mundo ocidental, baseado na máxima acumulação de capital, a natureza é apenas uma fornecedora de recursos para servir à extração de lucro. Com o discurso da importância do progresso, muitos países construíram um modelo de desenvolvimento agressivo à natureza, desconsiderando a finitude de seus recursos e a importância de se pensar no futuro da humanidade (LEFF, 2010).

Para que a questão ambiental não fique restrita apenas no discurso é preciso promover ações que fomentem atitudes de respeito ao meio ambiente. Neste processo, é fundamental que as pessoas despertem para o respeito para com a natureza, que esta seja vista como parte da humanidade e não como um elemento sobre o qual se deve investir irracionalmente para saciar os desejos da economia. Leonardo Boff $(2000$, p. 91$)$ fala sobre a importância do ato de cuidar, sendo que para este autor "cuidado significa, então, desvelo, solicitude, diligência, zelo, atenção, bom trato (...)". E esse cuidado deve ser estendido também para a natureza, pois sem ela a nossa sobrevivência fica

revista brasileira educação ambiental 
comprometida. Conhecer é essencial para que haja respeito, pois é muito mais fácil respeitar aquilo de que se tem o conhecimento. $\mathrm{O}$ mesmo vale para a natureza, pois quem a conhece de perto tem mais possibilidades de despertar para uma postura de respeito, comprometendo-se com ações de preservação a partir da compreensão de que a humanidade não está separada da natureza, mas é parte dela (RAPPAPORT, 1982). É necessário que a natureza deixe de ser apenas uma fornecedora de recursos, para sustentar uma economia onde a extração de lucro prevalece sobre todos os demais valores, e passe a ser vista como parte da humanidade. A Educação Ambiental tem um papel de protagonista neste processo, devendo para isso atuar no sentido de buscar formas de promover uma consciência crítica de modo a conduzir para uma transformação social, possibilitando a emergência de uma outra sociedade, onde o cuidado com o meio ambiente seja elevado à um nível maior de importância.

Marcatto, (2002) chama a atenção para a necessidade de dinamização dos métodos utilizados na Educação Ambiental, expostos na conferência de Tbilisi, salientando que esta deve lançar mão de "diferentes ambientes educativos e uma ampla gama de métodos para comunicar e adquirir conhecimentos sobre o meio ambiente, privilegiando as atividades práticas e as experiências pessoais" (MARCATTO,2002, p. 22).

Desta forma, o presente trabalho tem como objetivo geral analisar a importância da atividade de campo para a Educação Ambiental no ensino superior e especificamente: como essa atividade pode atuar no sentido de promover uma melhoria na assimilação de conteúdos trabalhados em sala de aula, destacando a relevância desta atividade para que seja despertada uma sólida conscientização sobre a necessidade de preservação ambiental.

Vários autores já demostraram a importância de atividades externas à sala de aula para a promoção da Educação Ambiental em potencializar o aprendizado dos alunos quando possibilita que esses sujeitos possam, mais do que apenas absorverem teorias, vivenciar experiências mais intensas (VIVEIRO; DINIZ, 2009; FERNANDES, 2007; GEBAUER; CARNIATTO, 2013). Contudo, é importante refletir sobre esse tipo de atividades também no ensino superior, mais especificamente na pós-graduação, como é o caso deste trabalho.

\section{Metodologia}

Este estudo foi realizado com um único grupo de estudantes de um curso de pós-graduação, tendo como foco a análise dos elementos subjetivos presentes neste coletivo durante uma atividade de campo, se caracterizando como um estudo de caso etnográfico. Atualmente há um grande número de estudos em diversas áreas que utilizam a etnografia como ferramenta, inclusive na educação, em que os estudos de caso etnográfico têm se constituído como uma importante ferramenta. De acordo com Lüdke e André (1986), esse tipo de estudo foca na singularidade do objeto estudado de modo que "a questão sobre o caso ser ou não 'típico', isto é, empiricamente representativo de uma Revbea, São Paulo, V. 12, № 5: 26-40, 2017. 
população determinada, torna-se inadequada, já que cada caso é tratado como tendo um valor intrínseco" (LÜDKE; ANDRÉ, 1986, p.18).

A pesquisa etnográfica, "caracterizada por ser uma pesquisa tradicional da Antropologia Clássica, requer cuidadosa observação ou imersão no cotidiano da população considerada" (SATO, 2001). Essa abordagem inicialmente se consolidou como uma ferramenta de estudo para se pesquisar as sociedades "primitivas", como os indígenas. A partir de meados do século $\mathrm{XX}$, com a introdução de novas teorias, como o estruturalismo, a antropologia passa a compreender que o modo como os "primitivos" produzem conhecimento, é parecido com o modo como os povos "civilizados" também o produzem. Desde então, e cada vez mais, as sociedades complexas (ocidentais) passam a fazer parte do objeto de estudo da antropologia. Se ao estudar grupos com cultura diferente da sua os antropólogos tinham que fazer um esforço para tornar o estranho familiar, hoje pesquisadores que utilizam a etnografia para estudar grupos que fazem parte de sua própria sociedade precisam fazer um exercício de "estranhamento" do familiar. De acordo com Wilson (1977, apud LÜDKE; ANDRÉ, 1986), uma das bases sobre as quais a pesquisa etnográfica se apoia é a hipótese qualitativa-fenomenológica, dentro da qual o pesquisador deve levar em conta "o quadro referencial dentro do qual os indivíduos interpretam seus pensamentos, sentimentos e ações " (LÜDKE; ANDRÉ, 1986, p.28). Segundo essa perspectiva, o pesquisador deve buscar um equilíbrio entre o seu papel de participante e observador para que possa "encontrar meios para compreender o significado manifesto e latente dos comportamentos dos indivíduos, ao mesmo tempo que procura manter sua visão objetiva do fenômeno" (LÜDKE; ANDRÉ, 1986, p.15).

A atividade de campo analisada neste estudo se constituiu de uma ação que produziu efeitos que contribuíram para a sensibilização dos participantes, no sentido de despertar para as questões ambientais. Diante disto, julgamos que a produção de conhecimento sobre a referida atividade, de modo a produzir um material capaz de descrever de forma mais fiel possível a experiência vivida pelos sujeitos durante a aula prática, possa servir de referência para futuras ações semelhantes. Diante da multiplicidade de elementos que pesaram na avaliação para a escolha da abordagem metodológica, uma das instigações para que este estudo pudesse captar os fenômenos humanos presentes no grupo estudado (como crenças, ideologias, valores etc.), foi a escolha de um método que estivesse à altura do desafio. Neste sentido, o método etnográfico se revelou como a ferramenta que melhor possibilitou a captação da subjetividade presente nos elementos que constituíam a ressignificação construída coletivamente pelos participantes das atividades educativas.

Considerando as limitações do tempo de convívio com o grupo, condicionado pelo cumprimento da carga horária das aulas, elegemos o estudo de caso etnográfico como uma forma de tentar captar o máximo de informações possíveis dentro das condições que tínhamos por conta curto período da atividade. Contudo, procuramos ampliar as fontes de captação de informações de modo obter um panorama mais detalhado do caso analisado,

revista brasileira educação ambiental 
com o objetivo de tornar o texto deste trabalho mais fiel aos fatos descritos. Como se trata de uma pesquisa qualitativa, a observação participante foi o método principal para a coleta de informações junto ao grupo estudado. Também foram aplicadas entrevistas semiestruturadas, cerca de seis meses depois da atividade de campo, com objetivo de conhecer com maior riqueza de detalhes o perfil dos participantes, bem como avaliar se estes ainda se sentiam influenciados pela atividade. Os acadêmicos entrevistados são identificados neste trabalho como A1, A2, A3 e A4. Houve também um retorno aos locais visitados para recolher informações junto aos profissionais responsáveis pela administração desses espaços. Concordamos com Lima quanto ao fato de que a etnografia não deve se restringir aos elementos observados em campo:

A questão é que a etnografia demanda da observação participante e do trabalho de campo uma disposição de pensamento, configurada para além do campo. Deixando claro que a qualidade necessária é pensar a partir dele. Assim, supõe-se que o antropólogo é capaz de manejar uma série de dados, de etnografias, de informações particulares e encaixálas de modo a construir uma teorização suficientemente significativa, mas com brechas de uma possível revisão perene. (LIMA, 2016, on-line).

Lüdke e André (1986) também reconhecem a variedade de fontes de informação para descoberta e coleta de novos dados nos estudos de caso etnográfico, argumentado que desta forma o pesquisador pode combinar ou confrontar essas informações. Elegemos ainda como referencial teórico neste trabalho, as reflexões de Paulo Freire (2003), autor que debate o caráter transformador da educação sendo que, "seu conceito de educação, compatível com 0 de Educação Ambiental, refere-se precisamente à ação simultaneamente reflexiva e dialógica, mediatizada pelo mundo (...)" (LOUREIRO, 2004, p.17).

\section{Pedagogia da autonomia e educação ambiental}

Diante dos efeitos deletérios que a intervenção humana vem causando no meio ambiente e das limitações das ações que atuam no sentido de reverter esse processo, torna-se necessário a intensificação da conscientização das pessoas para este tema. Os educandos não podem ser somente meros receptores de informações, mas principalmente, em relação a questões ambientais, devem ser sujeitos ativos e autônomos que além de aprender, são despertados para a transformação do mundo (FREIRE, 2003). Neste sentido, é necessário criar meios educativos que possibilitem aos educandos iniciarem uma reflexão sobre a necessidade de deixarem de ser apenas sujeitos passivos em uma sociedade destruidora para se tornarem sujeitos ativos de uma nova relação entre sociedade e natureza.

A atividade de campo, objeto desta pesquisa, ocorreu como uma das 
Desenvolvimento Rural Sustentável da Universidade Estadual do Oeste do Paraná-UNIOESTE, Campus de Marechal Cândido Rondon/PR, ocorrido no segundo semestre de 2016. Com uma carga horária total de 45 (quarenta e cinco) horas aula, a disciplina se constitui de 07 (sete) encontros (incluindo os dois dias de atividade de campo).

Com o objetivo de expor melhor a dinâmica das aulas, dividimos as mesmas em três etapas: Aulas presenciais, às terças-feiras nos meses de setembro a outubro; atividade de campo, nos dias 7 e 8 de novembro e, finalmente um último encontro, no dia 6 de dezembro, para a apresentação final de trabalhos que integram o instrumento avaliativo.

$\mathrm{Na}$ primeira fase, as aulas foram ministradas no Campus da Universidade, sendo que a metodologia utilizada foi a aula expositiva dialogada, tendo como temática condutora a discussão de textos sobre Educação Ambiental de autores como Enrique Leff, Marcos Sorrentino, Lucie Sauvé, entre outros. Também foram debatidos textos como o "Agenda 21" e "Carta da Terra".

Como demonstrado na Tabela 1, a turma era composta por uma diversidade considerável quanto a formação inicial dos mestrandos, com destaque para os bacharéis em Administração (com sete alunos).

Tabela 1: Formação acadêmica dos participantes da atividade de campo

\begin{tabular}{lc}
\hline \multicolumn{1}{c}{ FORMAÇÃO } & QUANTIDADE \\
\hline Administração & 07 \\
\hline Agronomia & 03 \\
\hline Ciências Biológicas & 01 \\
\hline Ciências Sociais & 01 \\
\hline Desenvolvimento Rural e Segurança Alimentar & 02 \\
\hline Economia & 01 \\
\hline Enfermagem & 02 \\
\hline Filosofia & 01 \\
\hline Fisioterapia & 01 \\
\hline Pedagogia & 01 \\
\hline Serviço Social & 01 \\
\hline Turismo & 01 \\
\hline
\end{tabular}

Fonte: Dados da pesquisa. Organizado pelos autores, 2017.

Verificou-se também uma heterogeneidade em relação a faixa etária dos estudantes, com idades variando entre 22 e 40 anos. Essa diversidade da turma, aliada a postura da professora, que permitia a livre expressão de ideias, contribuiu para que em alguns momentos, a diferença de pontos de vista entre os alunos ficasse um pouco mais evidente. Foi possível observar que a condução das aulas por parte da docente nesses momentos seria mais fácil se ela monopolizasse a fala, permitindo um mínimo de participação dos discentes. No entanto, percebeu-se que a prática adotada privilegiava a circulação de ideias, possibilitando a construção coletiva do conhecimento no sentido exposto por Paulo Freire (2003, p. 52), ao criar "as possibilidades para a sua própria produção ou a sua construção". Para isso, muitas vezes era necessário 
a mediação dos debates por parte da professora de modo que a diversidade de ideias fosse um fator de soma dos saberes e não de conflitos por eventuais divergências.

Contribuiu nestes momentos a dinâmica da aula quando a docente, em momentos-chave, lançava mão de atividades lúdicas que promoviam a integração entre os estudantes, quebrando a rigidez dos textos densos e conduzindo para que os debates ocorressem de forma mais harmoniosa. Sato (2003), propõe a diversificação das metodologias em Educação Ambiental, sendo que a autora sugere a "a utilização de jogos, simulações, teatros $e$ outras novas metodologias que auxiliam na familiarização dos estudantes com os problemas ambientais" (SATO, 2003 p. 41).

Esse ambiente menos conflituoso criado durante as aulas certamente contribuiu para o êxito da atividade de campo, produzindo já nos primeiros momentos da referida atividade um ambiente de maior afinidade no grupo, e as diferenças serviram na verdade, como um meio para promover a construção do conhecimento.

\section{Atividade de campo}

No dia 07 de novembro, a turma se reuniu no campus universitário, ainda de madrugada, para embarcar em uma viagem de aproximadamente duas horas até a cidade de Foz do Iguaçu-PR. Já no momento do embarque o clima de informalidade despertado durante as aulas se fazia presente. Por volta das $8 \mathrm{~h}$ da manhã o grupo desembarcou na primeira parada, o Parque das Aves, em Foz do Iguaçu.

O Parque das Aves é um zoológico particular criado pelo casal Dennis e Anna Croukamp. A ideia de criar o esse espaço começou em uma viagem à África, na qual o casal ganhou um filhote de Papagaio-do-Congo, o qual despertou o amor e admiração em Dennis pelas aves. Anos depois um amigo sugeriu que a família se mudasse para Foz do Iguaçu para construir um parque de crocodilos, mas Dennis gostava de aves, e na cidade de Foz do Iguaçu encontrou o local ideal para fundar um parque temático dedicado à conservação desses animais (PARQUE DAS AVES, s/a).

O mesmo foi inaugurado em 1994 e tem como objetivos a promoção de atividades educacionais que despertem a consciência ambiental e estimulem ações de conservação no presente e no futuro; pesquisas na área de conservação ambiental; desenvolvimento de projetos de reintrodução de espécies nas áreas protegidas do estado do Paraná e reprodução em cativeiro das espécies mantidas no parque, com ênfase a aves em risco de extinção. $O$ Parque é divido em três áreas: a área da trilha para visitação, onde se localizam a maioria dos recintos (Essa é a única área de acesso dos visitantes); a área interna onde encontram-se o Hospital Veterinário, a sala de necropsia e o biotério; os recintos da área interna, a cozinha das aves, a cozinha dos funcionários e os setores administrativos; e a área onde encontra- 
se a quarentena, a manutenção, a Educação Ambiental, alguns espaços extras, a sala de grilos, a área de descanso dos funcionários, e um estacionamento interno (PARQUE DAS AVES, s/a).

O Parque das Aves conta com uma grande área de trilha para visitação, onde são encontrados a maior parte dos recintos. Em sua grande maioria, os cativeiros são mistos, abrigando diferentes espécies de aves ou répteis. Alguns dos locais destinados à visitação são espaços de imersão, possibilitando um contato maior entre os visitantes e os animais. Esses Lugares possuem um corredor de segurança na entrada e outro na saída, para evitar fuga de animais. Outro tipo de recinto é o de reprodução, onde ficam casais de aves que se tem o objetivo de reproduzir. Independentemente do tipo de ambiente, todos contam com uma área de manejo.

No parque das aves a turma foi recepcionada por biólogas, funcionárias do local e conduzida para uma sala onde assistiram a uma palestra sobre as ações do local com relação à preservação de espécies. Além do trabalho de reprodução em cativeiro, o zoológico recebe aves e outros animais apreendidos pela Polícia Militar Ambiental e que não têm mais condições de serem soltos novamente na natureza. Após receber essas informações, o grupo realizou uma visita ao acervo do parque, guiada pelas funcionárias que haviam proferido a palestra e que continuaram transmitindo as informações durante o trajeto. Os recintos, por permitirem a visualização de quase todas as aves e demais animais sem a intermediação de telas ou grades, oportunizaram uma experiência mais intensa ao proporcionar aos visitantes o contato com os animais como se estivessem na natureza (Figura 1).

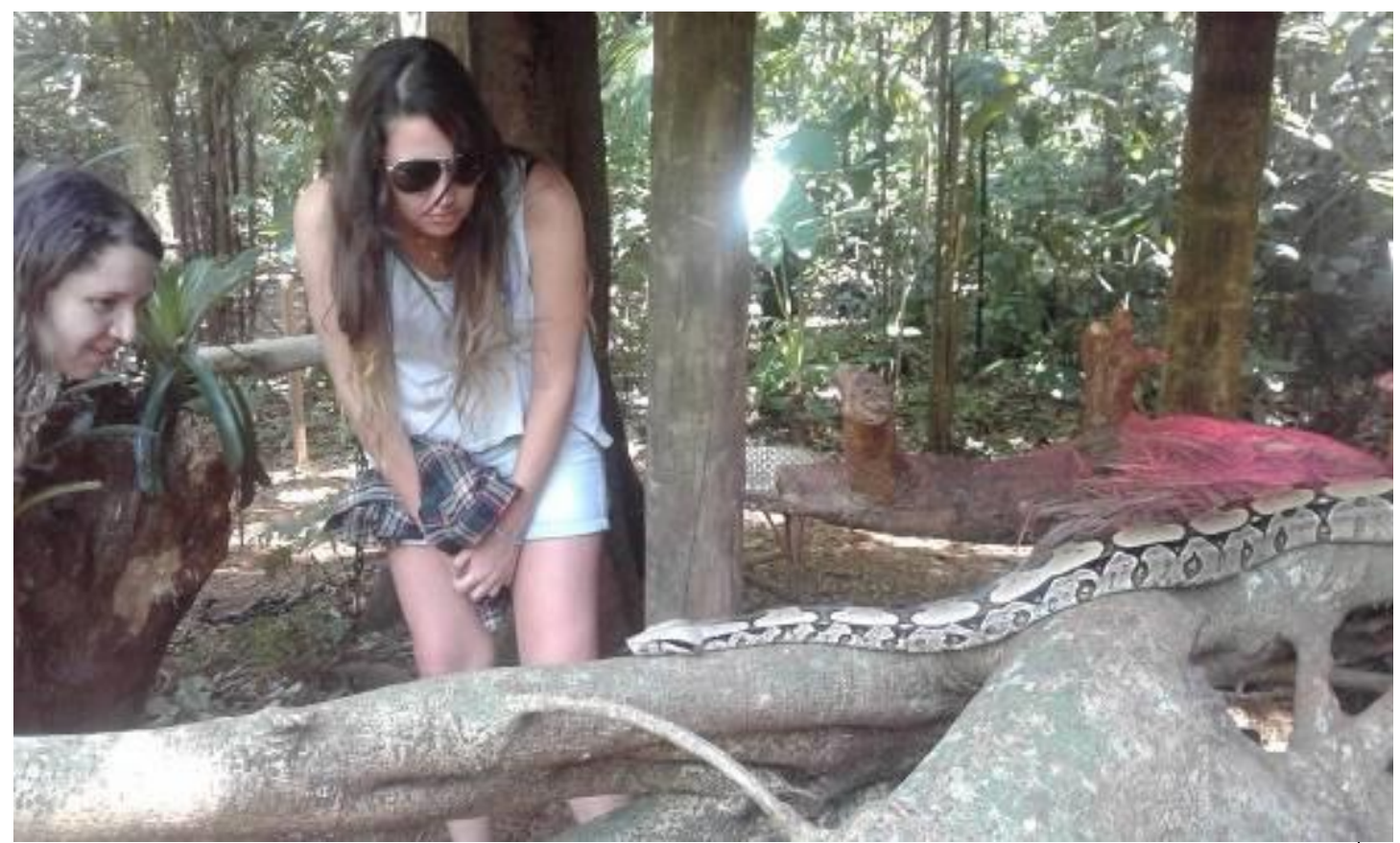

Figura 1: Visita ao Parque das Aves.

Fonte: Emerson Ferreira da Silva (2016). 
Posteriormente, o grupo deslocou-se ao Parque Nacional do Iguaçu, realizando um passeio supervisionado, também realizado sob o acompanhamento de uma funcionária do local que passava informações sobre a fauna e a flora do parque, além da história do mesmo. Após uma longa caminhada pelas trilhas em meio à natureza, com paradas estratégicas para ouvir as informações da guia, o grupo pode apreciar uma visita às Cataratas do Iguaçu, uma das maiores belezas naturais do mundo.

$\mathrm{O}$ fato do fato das visitas serem realizadas em espaços onde haviam funcionários locais para assessorar o grupo, agregou muito pedagogicamente, pois geralmente em "visitas monitoradas oferecidas por uma instituição, com um itinerário pré-determinado, o trabalho do educador é aparentemente facilitado, uma vez que se supre a necessidade de que conheça detalhadamente todo o ambiente visitado" (VIVEIRO; DINIZ, 2009, p.6).

O Parque Nacional do Iguaçu (PNI) é uma Unidade de Conservação de proteção integral, criado em 10 de janeiro de 1939 pelo Decreto-Lei no 1035. Com um território de aproximadamente 185.000 hectares, está localizado no Oeste do Estado do Paraná e abriga milhares de espécies silvestres da fauna e da flora. Com 420 quilômetros de perímetro, abrange 14 Municípios em seu entorno e limita-se em mais de $60 \mathrm{~km}$ com o Parque Nacional do Iguazu (Argentina), integrando o mais importante contínuo biológico do Centro-Sul da América do Sul (BERGALLO; CONDE, 2001).

Pelo reconhecimento da importância da conservação desta área e de toda sua biodiversidade, em 1986 foi intitulada Patrimônio Natural da Humanidade pela UNESCO. Abrigando uma das sete maravilhas da Natureza, as Cataratas do Iguaçu, o PNI foi criado com o objetivo de conservação da biodiversidade e seus ecossistemas conforme descrito na Lei Federal 9.985/00, que instituiu o Sistema Nacional de Unidades de Conservação, sendo permitido o uso indireto de seus recursos naturais, tais como: o desenvolvimento de pesquisas cientificas, atividades de Educação Ambiental, recreação em contato com a natureza e turismo ecológico (BERGALLO; CONDE, 2001).

Em 1962, foi construída no PNI a Escola de Educação Ambiental Escola Parque, concebida como uma escola pública que visava atender os filhos de funcionários e produtores do entorno do Parque. Em 1998, devido ao número reduzido de alunos, a escola foi desativada e passada para o IBAMA (Instituto Brasileiro do Meio Ambiente e dos Recursos Naturais Renováveis), tornando-se a Escola de Educação Ambiental do Parque Nacional do Iguaçu Escola Parque e desde então vem desenvolvendo atividades de Educação Ambiental do Parque Nacional (IBAMA, 2006).

O segundo dia de atividades iniciou com a visita ao Complexo Turístico Itaipu. Logo pela manhã, o grupo conheceu o Eco Museu, um espaço destinado a resgatar a memória da construção da Usina Hidroelétrica de Itaipu, bem como sobre a fauna e flora da região. O Eco Museu de Itaipu foi criado para conservar a história da usina e da região em que foi construída a hidrelétrica. Ele expõe desde a ocupação da região do complexo na margem 
brasileira até os projetos de conservação ambiental da Itaipu. Dentro desse roteiro, estão atrações como os espaços temáticos de água e energia, cenários históricos, maquetes, itens de acervo, totens eletrônicos, além de uma réplica do eixo de uma turbina em atividade, com direito aos ruídos característicos do coração da usina. Um painel de fotos em tamanho " $3 \times 4$ ", e o Memorial do trabalhador homenageiam as mais de 120 mil pessoas que trabalharam na construção da hidrelétrica, além de espaços temporários com exposições das mais diversas. (ITAIPU BINACIONAL, s/d).

Também neste local a turma foi recepcionada por profissionais que palestraram sobre as ações da Itaipu para com o meio ambiente na região da bacia do Rio Paraná, para só então conhecerem o acervo do museu. Ainda durante o período da manhã foram realizadas visitas aos tradicionais pontos turísticos da usina, como a barragem e o mirante.

A tarde do segundo dia de atividades iniciou com uma visita ao Refúgio Biológico Bela Vista que é uma área de preservação que possui uma extensão total de 1.920 ha, estando localizada ao lado da represa da usina de Itaipu Binacional. No local são desenvolvidas atividades que envolvem a reprodução de animais silvestres em cativeiro, produção de mudas destinadas ao reflorestamento das margens da barragem e condução de experimentos relacionados à flora e à fauna da região. Nele está localizado o Criador de Animais Silvestres de Itaipu Binacional (CASIB), onde são reproduzidos, em cativeiro, os animais silvestres usados para o repovoamento das orlas, refúgios e reservas do lado brasileiro do lago de Itaipu. Embora ainda não disponha de infraestrutura destinada ao turismo, um razoável número de pessoas visita todos os anos o Refúgio, com o objetivo de conhecer as atividades ali desenvolvidas. Além disso, o local recebe regularmente grupos de alunos de escolas da região, que além de conhecer os trabalhos realizados no espaço, participam de atividades de Educação Ambiental, orientadas por educadores ambientais do Eco Museu de Itaipu (SATTLER, 2003).

\section{Apropriação do conhecimento de forma coletiva}

O processo de socialização é algo inerente aos seres humanos e ocorre o tempo todo. Dentro desse processo, as relações no interior de grupos sociais têm papel significativo, visto que permitem a construção de identidades próprias entre os sujeitos. Para o antropólogo Gilberto Velho (2003), nas sociedades complexas as configurações sociais podem atuar no sentido de criar grupos que constroem identidades especificas, mesmo em um curto período de contato. A formação de um grupo com uma identidade específica pode acontecer em várias situações, como no grupo analisado neste trabalho, que apesar de ter tido um período relativamente curto de convívio, a integração 
criada entre os participantes produziu uma identidade própria se configurando como um ethos ${ }^{5}$.

Durante o trabalho de campo analisado nesta pesquisa, a combinação das explicações técnicas fornecidas pelos profissionais dos locais visitados com o clima de informalidade, criado durante as aulas e intensificado durante os dois dias de visita, proporcionaram, segundo relato da maioria dos entrevistados, um ambiente em que mais do que receber informações, pôde-se vivenciar experiências singulares.

A variedade de formação entre os participantes, aliada ao ambiente de informalidade, também foi um elemento que permitiu que a troca de informações acontecesse naturalmente entre os todos durante a atividade de campo, principalmente nas caminhadas. Havia no grupo pessoas com conhecimentos sobre botânica, cultura indígena, agronomia etc. Isso permitia que a cada momento os diversos pontos de vista pudessem ser compartilhados de modo a facilitar a produção de um conhecimento coletivo, tendo o contato com a natureza como ponto de unidade.

Para Leff, o saber ambiental se forma nas ações sociais, não apenas através de conhecimento objetivo, mas sobretudo na construção de utopias, no desejo de conhecer, através de uma multiplicidade de significados, aquilo que as ciências ignoram. Para ele:

O saber ambiental emerge de um diálogo de saberes, do encontro de seres diferenciados pela diversidade cultural, orientando o conhecimento para a formação de uma sustentabilidade partilhada. Ao mesmo tempo, implica a apropriação de conhecimentos e saberes dentro de distintas racionalidades culturais e identidades étnicas. (LEFF, 2009, p. 19).

Para Brandão (2002, p. 293), a educação é uma "vivência solidária de criação de sentidos ao longo da vida e em cada um dos momentos da vida de cada ser humano". Apesar da diversidade da turma, ficou claro que durante a atividade se formou um ethos específico, baseado na cumplicidade e no compartilhamento de momentos que promoveram uma aprendizagem incomum para a maior parte dos discentes, que se dava de forma coletiva e informal.

Vale ressaltar que a disciplina não era obrigatória, o que dá a entender que os acadêmicos que a escolheram tinham um certo interesse por questões ambientais, o que se configurou como um elemento de unidade entre os membros do grupo. Esse interesse em comum contribuiu para que a empatia entre os participantes aumentasse a cada aula.

${ }^{5}$ Nas ciências sociais o termo ethos geralmente é empregado para designar o conjunto de valores que definem um grupo social, mesmo que este grupo faça parte de um grupo maior, o que é comum em sociedades complexas.

Revbea, São Paulo, V. 12, № 5: 26-40, 2017. 
O clima de cumplicidade ficou manifesto no final da atividade de campo, quando foi oportunizado um momento para que cada um que quisesse pudesse relatar suas impressões sobre a experiência. Foi possível observar depoimentos carregados de emoção, demonstrando o quanto foi marcante a experiência para cada um. Para Viveiro e Diniz (2009), a atividade de campo, diferentemente das aulas tradicionais em sala, promovem a criação de laços entre os participantes sendo que, os estreitamentos desses laços afetivos fazem com que a atividade de campo se consolide como uma estratégia de ensino e não como um mero passeio. Para as autoras "ao envolver aspectos afetivos e emocionais positivos, uma atividade de campo favorece a motivação intrínseca, despertando uma atração que impulsiona o estudante a aprofundarse nos aspectos estudados" (VIVEIRO; DINIZ, 2009, p.4). Também nas entrevistas realizadas quase seis meses após a atividade de campo, foi possível verificar o quanto os resultados da atividade ainda continuam aparecendo de forma expressiva como demostram os fragmentos dos depoimentos transcritos a seguir:

As viagens técnicas oportunizam novas experiências e, ao analisar o contexto que atuamos, fazemos um paradoxo entre essas realidades. A experiência que se tem através de uma visita técnica, dia de campo, etc. nos aproxima de diferentes realidades e estimulam nossa criatividade para a concretização de atividades diferenciadas no nosso contexto. (A1)

\section{Outro participante descreveu que a}

A disciplina foi de grande importância, pois a partir da mesma pode-se ter uma noção mais clara do que é Educação Ambiental e de como está presente no dia a dia e que existe vários órgãos que realizam esses tipos de práticas que visam um melhor desenvolvimento da região, ensinando a população a pensar de maneira sustentável, buscando uma melhor interação entre o homem e o meio ambiente e a necessidade de educar desde cedo para que todos tenham princípios que visam um cuidado com o meio ambiente, pensando não só agora, mais também no futuro. (A2)

Um outro aluno sintetizou sua experiência com as seguintes palavras:

Através da disciplina, das visitas, comecei a praticar algumas simples atitudes do dia a dia que até então não o fazia, como por exemplo, separar o lixo orgânico dos demais, evitar os copos descartáveis que são muito utilizados no ambiente acadêmico etc. (A3) 
Os efeitos positivos provocados pela atividade de campo se tornam ainda mais relevantes se considerarmos que a atividade docente está no horizonte da maioria dos participantes. A pesquisa revelou que entre os 22 discentes entrevistados, 10 atuam como professores na educação básica, técnica ou superior. Embora outros 11 entrevistados tenham afirmado não serem professores, todos que responderam à pesquisa (apenas um não respondeu) disseram que pretendem atuar como docentes, principalmente na educação superior, o que é muito comum entre estudantes que procuram uma pós-graduação Stricto Sensu.

Um dos participantes, que já atua como professor universitário, relatou que já levou uma de suas turmas até a cidade de Foz do Iguaçu para um trabalho semelhante, o que demonstra o caráter multiplicador da atividade, ao despertar nos membros do grupo o desejo repassar o conhecimento adquirido, contribuindo assim para a multiplicação da Educação Ambiental a partir da diversidade de métodos.

\section{Considerações finais}

Diante das necessidades de divulgação da questão ambiental na sociedade atual a criação de práticas que promovam a Educação Ambiental é de extrema importância. Práticas educativas que despertem nos educandos do verdadeiro sentido de preservação ambiental, fazendo com que eles possam ter experiências marcantes sobre a necessidade de cuidado para com a natureza, trazem uma importante contribuição neste sentido.

Há muitos relatos de efeitos satisfatório com atividades de campo aplicados ao ensino (VIVEIRO; DINIZ, 2009; FERNANDES, 2007; GEBAUER; CARNIATTO, 2013). A grade maioria desses trabalhos, no entanto, apresentam experiências com estudantes da educação básica. A prática relatada neste trabalho mostra que tal atividade também pode agregar muito ao ensino superior, contribuindo para assimilação dos conteúdos de forma mais satisfatória.

Apesar de todo o conhecimento que o estudo de textos acadêmicos pode trazer, a atividade prática tem um impacto marcante naqueles que passam por esta experiência, figurando como uma complementação que produz experiências bastante positivas no processo de aprendizagem. $\mathrm{A}$ união de teoria e prática, contribui para que os estudantes se tornem sujeitos ativos da aprendizagem fazendo com que o conhecimento seja não apenas recebido de cima, mas, sobretudo construído coletivamente a partir do momento em que é vivenciado.

A educação tem um papel importante na construção de uma nova sociedade, pautada em um maior respeito para com a natureza e para com as pessoas. Os relatos dos participantes ao final da atividade, assim como nos depoimentos coletados nas entrevistas, mostram como a atividade de campo, conduzido de maneira profissional, contribui para a sensibilização para as questões ambientais. Mais que um simples passeio, as vistas mediadas Revbea, São Paulo, V. 12, № 5: 26-40, 2017. 
potencializaram as possibilidades de um aprendizado conjunto no sentido de fortalecer os laços entre os participantes, devido a intensidade do convívio em ambiente informal (VIVEIRO; DINIZ, 2009).

\section{Referências Bibliográficas}

BACCI, D.C.; SILVA, R.L.F.; SORRENTINO, M. Educação Ambiental e universidade: diagnóstico disciplinar para construção de uma política ambiental. Anais do VIII Encontro de Pesquisa em Educação Ambiental, Rio de Janeiro, 2015.

BERGALLO, H.G.; CONDE Y.V. O Parque Nacional do Iguaçu e a estrada do Colono. Ciência Hoje, 29, 2001. p.37-39.

BOFF, L. Saber cuidar: ética do humano: compaixão pela terra. 9. ed. Petrópolis: Vozes, 1999.

BRANDÃO, C.R. A educação popular na escola cidadã. Petrópolis, RJ, Vozes, 2002.

FERNANDES, J.A.B. Você vê essa adaptação? A aula de campo em ciências entre o retórico e o empírico. São Paulo, 2007. 326p. Tese (Doutorado em Educação) - Faculdade de Educação, Universidade de São Paulo, São Paulo, 2006.

FREIRE, P. Pedagogia da Autonomia: Saberes necessários à prática educativa. São Paulo, Paz e Terra, 2003.

GEBAUER, I.C.L.; CARNIATTO, I. Educação Ambiental em eco-trilha do Parque Nacional do Iguaçu. Anais do CIRPEA - I Colóquio Internacional da Rede de Pesquisa em Educação Ambiental por Bacia Hidrográfica e do XIV EPEA - Encontro Paranaense de Educação Ambiental. Cascavel: Unioeste, 2013. v. 01. p. 116-127.

IBAMA. Como o Ibama exerce a Educação Ambiental. Coordenação Geral de Educação Ambiental. Brasília: Edições Ibama, 2002. 32 p.

ITAIPU.Ecomuseu. Disponível em:https://www.itaipu.gov.br/turismo/ecomuseu. Acesso em: 14 de agosto de 2017.

LEFF, E. Complexidade, racionalidade ambiental e diálogo de saberes. Educação \& realidade, v. 34, n. 3, 2009.

LEFF, E. Discursos sustentáveis. São Paulo: Cortez, 2010.

LIMA, A.O. Da importância da etnografia: a observação participante e o trabalho de campo. [S.I]: Blog Observare, 2016. Disponível em:< https://observare.slg.br/2016/10/04/da-importancia-da-etnografia $>$.

Acesso em: 31 de julho de 2017.

LOUREIRO, C.F.B. Educar, participar e transformar em Educação Ambiental. Revista Brasileira de Educação Ambiental, Brasília, v. 1, p. 13-20, 2004. 
LÜDKE, M.; ANDRÉ, M.E. Pesquisa em educação: abordagens qualitativas. São Paulo: EPU, 1986.

MARCATTO, C. Educação Ambiental: conceitos e princípios. Belo Horizonte: FEAM, 2002. Disponível em: <http://www.scribd.com/doc/702363/EducacaoAmbiental-ConceitosPrincipios.> Acesso em: 28 out. 20016.

MARCONDES FILHO, C. 0 que todo cidadão precisa saber sobre ideologia. Global Editora, 1985.

PARQUE DAS AVES. Historia. Disponível em: http://www.parquedasaves.com.br/pt/historia.html. Acesso em: 14 de agosto de 2017.

PEIRANO, M. A favor da etnografia. Rio de Janeiro: Relume-Dumará, 1995.

RAPPAPORT, R. A Natureza, cultura e antropologia ecológica. In: SHAPIRO, H.L. Homem, Cultura e Sociedade. São Paulo: Martins Pontes, 1982.

SATO, M. Educação Ambiental. São Carlos: Rima, 2003.

SATO, M. Apaixonadamente pesquisadora em Educação Ambiental. Educação: Teoria e Prática, v. 1, n. 2, p. 24, 2001.

SATTLER, M.A. et al. Estratégias sustentáveis para o Refúgio Biológico Bela Vista. Anais do III ENECS-ENCONTRO NACIONAL SOBRE EDIFICAÇÕES E COMUNIDADES SUSTENTÁVEIS, v. 1, Foz do Iguaçu, 2003.

VELHO, G. Projeto e metamorfose, antropologia das sociedades complexas. Rio de Janeiro: Jorge Zahar, 2003. 